\title{
METODOLOGIAS ATIVAS NO ENSINO DE SAÚDE DO IDOSO: uma revisão bibliográfica
}

ACTIVE METHODOLOGIES IN HEALTH EDUCATION FOR THE ELDERLY: a literature review

METODOLOGÍAS ACTIVAS EN EDUCACIÓN SANITARIA PARA PERSONAS MAYORES: una revisión de la literatura

\section{Ana Kleiber Pessoa Borges}

Bióloga, Mestre e Doutora pela UNESP/Rio Claro, SP. Docente na Graduação de Enfermagem na UFT (Universidade Federal do Tocantins, Palmas/TO). anakleiber@uft.edu.br.

0000-0003-1865-2595

\section{Ana Gabriela Ferreira Brito}

Mestranda em Ensino em Ciências e Saúde (UFT) Graduada em Psicologia (CEULP/ULBRA). anagfbrito@gmail.com.

0000-0002-8533-7176

\section{Ilaíse Brilhante Batista}

Mestranda em Ensino em Ciências e Saúde (UFT). Pós Graduada em Urgência e Emergência/UTI (INESPO). Graduada em Enfermagem (UFMA). ilaisebrilhante@gmail.com.

\section{0-0001-5705-5254}

\section{Jéssica da Silva Marinho}

Mestranda em Ensino em Ciências e Saúde (UFT). Graduada em Enfermagem (UFT).

jess.smarinho@gmail.com.

0000-0001-8950-7083

\section{Erenilde Barbosa da Silva Costa \\ Graduada em Farmácia (CEULP/ULBRA) erenildebarbosa@hotmail.com. \\ 0000-0001-5188-7930}

Mislene Ferreira Xavier de Melo

Graduada em Enfermagem

mislene melo@mail.uft.edu.br.

(UFT)

\begin{abstract}
Correspondência: Universidade Federal do Tocantins. Centro de Estudos Superiores de Grajaú. Rua da Mangueira, S/N - Bairro Rodoviário - CEP 65. 940-000 - Grajaú, MA - BRASIL. E-mail: cesgra@uema.br.
\end{abstract}

Recebido em: 12.10.2020.

Aceito em: 20.11.2020.

Publicado em: 01.01.2021.

\begin{abstract}
RESUMO:
Esta pesquisa objetivou analisar as práticas em metodologias ativas utilizadas no ensino de saúde do idoso. Realizou-se a busca da amostra nas bases de dados LILACS, SciELO, Periódicos CAPES e buscador Google Scholar. Foram selecionados 07 artigos e sua análise resultou nas categorias "o uso de metodologias ativas para o ensino em saúde ao idoso" e "o uso das principais metodologias ativas na formação de acadêmicos, profissionais e cuidadores". As demandas sociais atuais exigem metodologias de ensino que possibilitem uma formação crítica, reflexiva e problematizadora. Sugere-se a necessidade de mais pesquisas sobre esse tema, tanto no âmbito acadêmico, quanto em outros contextos de ensino, como a educação em saúde e permanente.
\end{abstract}

PALAVRAS-CHAVES: Metodologia ativa; Saúde; Idoso.

0000-0002-9099-3960

\section{Introdução}

O envelhecimento populacional é um fenômeno que vem ocorrendo mundialmente e, em razão da redução da taxa da natalidade e aumento da porcentagem de idosos a pirâmide etária encontra-se invertida. Outros fatores que contribuem para essa inversão são as descobertas farmacológicas e tecnológicas proporcionadas pela ciência, garantindo assim à população um prolongamento da expectativa de vida (MELO, 2017).

O processo de envelhecer ocorre naturalmente, de modo irreversível e é multifatorial (CAMARANO, 2008; VIANA et al, 2013). Geralmente, as percepções acerca do envelhecimento são carregadas de estereótipos, que limitam as possibilidades de conceber essa parcela da população em toda sua potencialidade. Contudo, o aumento 
da longevidade tem proporcionado novas perspectivas para esse público, que antes era visto apenas como um "peso" social, mas, no contexto atual é um sujeito com maiores oportunidades de redefinir e viver a velhice com mais plenitude (OMS, 2015).

Para tanto, uma readequação nas políticas públicas com propósito de abranger a inserção dessa geração nos contextos sociais é necessária, contribuindo assim para um novo olhar sobre a velhice (FELIPE; SOUSA, 2018). Em relação a isto a Política Nacional da Pessoa Idosa (PNPI) tem dado ênfase nos dias atuais a promoção do envelhecimento saudável focado no desenvolvimento de ações que promovam a capacidade funcional, adoção de hábitos saudáveis na velhice, prevenção de riscos de queda, perdas funcionais, deficiências na alimentação e ainda ações que garantam a diminuição do isolamento social do idoso (VERAS; OLIVEIRA, 2018).

Referente a isso, a PNPI propõe que as Instituições de Ensino Superior tenham maior atenção com este público, promovendo por meio de estratégias de ensinoaprendizagem a formação de profissionais capacitados para atuarem diante dos novos cenários que o envelhecimento tem colocado para a sociedade, de modo a contribuírem para o desenvolvimento de um envelhecimento saudável. Para isso, é necessária a inserção de matérias que abranjam a área da Gerontologia e Geriatria nos currículos acadêmicos, uma vez que essas são áreas de estudo dedicadas ao envelhecimento e saúde do idoso (CARVALHO, 2015).

Nesse contexto, entende-se que a didática e a metodologia empregadas no ensino são tão importantes quanto os conteúdos ministrados. O ensino tradicional, entretanto, não tem acompanhado essas demandas educacionais, uma vez que está fadado a exposição de conteúdos e ao pouco envolvimento dos estudantes nos processos de aprendizagem. Dessa forma, o ensino precisa entrar em sintonia com as dinâmicas sociais e de educação, proporcionando por meio de metodologias mais participativas, a formação de sujeitos reflexivos e conscientemente envolvidos na construção de conhecimentos que sejam significativos para modificar os contextos onde estão inseridos (PAIVA et al, 2016; DUARTE, 2018).

Em relação a isso, a Resolução $n^{\circ} 569$ de 2017 dispõe sobre a introdução nas Diretrizes Curriculares Nacionais (DCN) para os cursos na área da saúde de propostas pedagógicas inovadoras, com a utilização de metodologias diversificadas que promovam a participação e autonomia do estudante, integrando os conteúdos com propósito de promover uma aprendizagem baseada em ação-reflexão-ação. As DNC devem ainda considerar a abordagem de temáticas relacionadas ao envelhecimento populacional e ao surgimento de doenças crônicas não transmissíveis (DCNT), visto a pertinência que esses assuntos têm alcançado no âmbito social, político e de saúde (BRASIL, 2017). 
Entende-se, então, que as metodologias ativas têm potencial para promover essa formação engajadora, pois alicerçam o ensino-aprendizado em situações reais ou simuladas, com o objetivo de resolução de problemas e inserção do estudante dentro de múltiplas realidades (BERBEL, 2011). Assim, este trabalho tem como objetivo analisar as práticas em metodologias ativas utilizadas no ensino de saúde do idoso entre os anos de 2010 a 2020.

\section{Método}

No presente estudo foi realizada uma revisão de literatura integrativa, que consiste em um método que permite a análise de materiais científicos de estudos já publicados de maneira ampla e sistematizada com intuito de gerar novos conhecimentos (NETO et al, 2016).

Para realização do estudo seguiu-se as seguintes etapas: definição do tema de pesquisa, delimitação dos critérios de inclusão e exclusão, seleção dos artigos nas bases de dados, categorização dos estudos, avaliação dos estudos pré-selecionados, interpretação dos resultados e apresentação da revisão.

Para obtenção dos periódicos pertinentes ao tema foram utilizadas as bases de dados online, LILACS (Literatura Latino-americana e do Caribe em Ciências da Saúde), SciELO (Scientific Eletronic Library Online), Periódicos CAPES e o buscador Google Scholar (Google acadêmico).

Os descritores utilizados para a seleção foram: metodologia ativa, saúde e idoso, gerando assim o seguinte string de busca: "metodologia ativa" AND idoso AND saúde, com o intuito de localizar estudos.

Como critérios de inclusão estabelecidos estão: publicações no período de 2010 a junho de 2020 com disponibilidade online do texto na íntegra, no idioma português, publicados em periódicos. Não foram incluídos artigos duplicados, estudos publicados em anais de congressos, resumos expandidos, livros, trabalhos de conclusão de curso, teses e dissertações.

A busca gerou 1.403 resultados sendo o Google Acadêmico o buscador que apresentou maior número de retorno de artigos. Seguindo os critérios de inclusão e exclusão, 1.024 artigos foram retirados, restando 19 trabalhos. Após uma leitura mais aprofundada 08 trabalhos foram excluídos por não estarem de acordo com a proposta deste trabalho, por fim, 04 trabalhos foram excluídos por estarem duplicados entre as plataformas. A amostra final obteve um quantitativo de 07 trabalhos. A sistematização do procedimento de busca está ilustrada na Figura 1. 
Todos os artigos foram lidos na íntegra e individualmente. Os indicadores para fundamentação e interpretação para os principais resultados foram dispostos em um quadro sinóptico contendo informações de cada pesquisa, com os seguintes tópicos: ano de publicação, título, autores, objetivo, metodologia e periódicos.

Para o tratamento e interpretação dos resultados, os dados foram codificados através de recortes estrutural e simultâneo de cada artigo, gerando assim núcleos relacionados a análise dos conteúdos dos artigos. A análise foi realizada por meio de categorização, que de acordo com Minayo (1992, apud BARDIN, 2011) consiste no desmembramento e classificação do texto de acordo com categorias agrupadas analogicamente. Foram definidas as categorias de análises de acordo com os critérios semânticos, originando as seguintes categorias temáticas: "O uso de metodologias ativas para o ensino em saúde ao idoso" e "O uso das principais metodologias ativas na formação de acadêmicos, profissionais e cuidadores". Posteriormente foram observadas as divergências e convergências existentes entre autores diferentes a partir da interpretação dos resultados obtidos.

Figura 1. Sistematização para seleção das amostras.

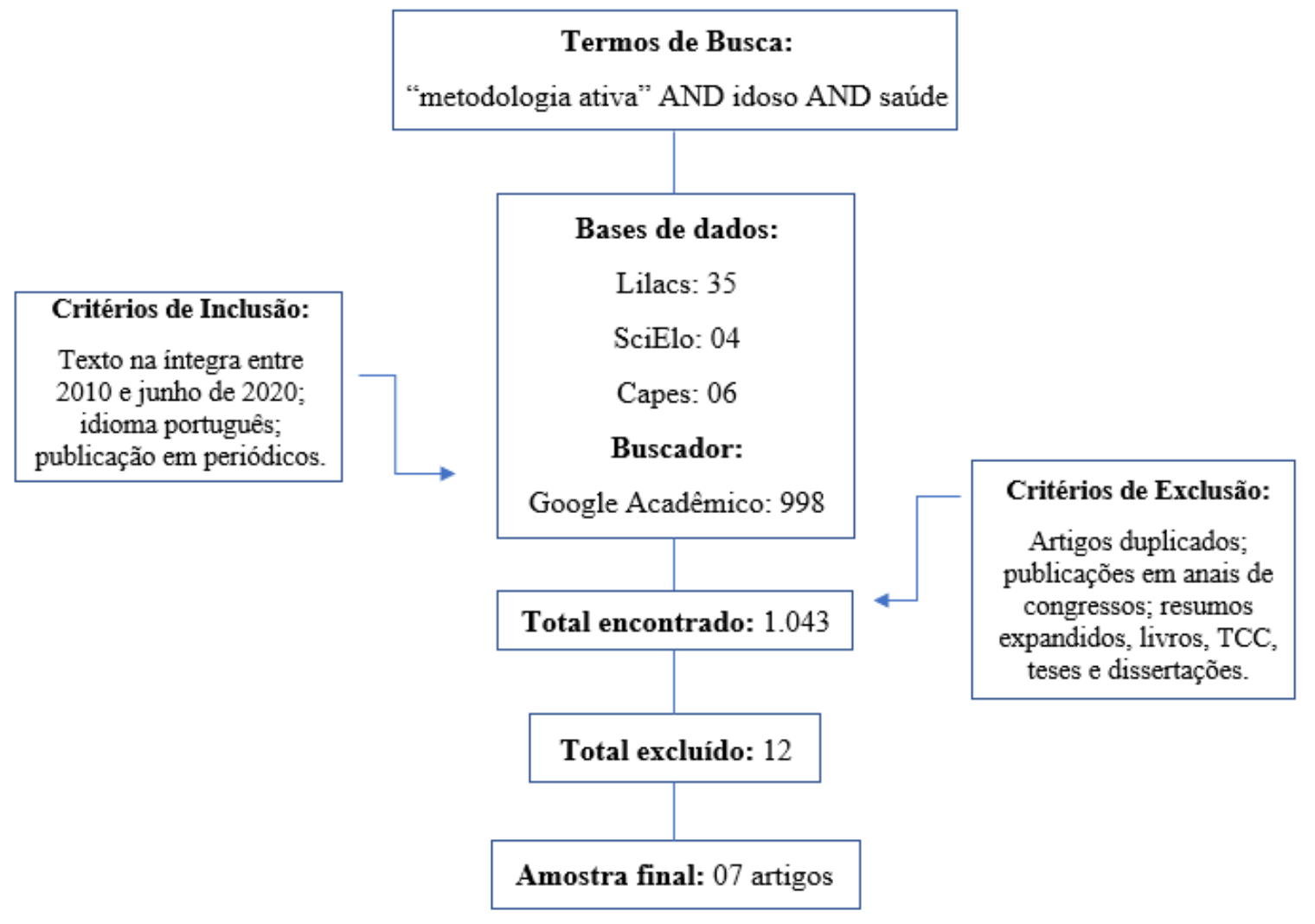

Fonte: autores, 2020 


\section{Resultados e Discussão}

Após as buscas nas bases de dados utilizando o cruzamento dos descritores citados na metodologia, obtiveram-se os resultados descritos no Quadro 1.

Quadro 1. Dados dos artigos utilizados nesta pesquisa.

\begin{tabular}{|c|c|c|c|c|c|}
\hline Ano & Título & Autores & Objetivo & Metodologia & Periódicos \\
\hline 2013 & $\begin{array}{l}\text { O impacto do } \\
\text { estágio na } \\
\text { formação do } \\
\text { farmacêutico no } \\
\text { cuidado ao } \\
\text { paciente idoso }\end{array}$ & $\begin{array}{l}\text { ALVES, M. I. } \\
\text { G.; RIOS, P. } \\
\text { S. S.; RIOS, } \\
\text { M. C. }\end{array}$ & $\begin{array}{l}\text { Avaliar a efetivação } \\
\text { do Estágio } \\
\text { Farmacêutico como } \\
\text { eixo indutor ao } \\
\text { exercício pleno da } \\
\text { prática de Atenção } \\
\text { Farmacêutica, } \\
\text { através da análise de } \\
\text { percepções. }\end{array}$ & $\begin{array}{c}\text { Estudo } \\
\text { analítico, } \\
\text { quantitativo e } \\
\text { qualitativo, } \\
\text { transversal. }\end{array}$ & $\begin{array}{l}\text { Cadernos de } \\
\text { Graduação - } \\
\text { Ciências } \\
\text { Biológicas e da } \\
\text { Saúde }\end{array}$ \\
\hline 2017 & $\begin{array}{l}\text { Estratégias } \\
\text { educativas para } \\
\text { promoção da } \\
\text { saúde de idosos } \\
\text { de um centro de } \\
\text { convivência }\end{array}$ & $\begin{array}{c}\text { OLIVEIRA, F. } \\
\text { A., et al. }\end{array}$ & $\begin{array}{c}\text { Descrever a } \\
\text { realização de } \\
\text { estratégias } \\
\text { educativas } \\
\text { extensionistas para } \\
\text { promoção da saúde } \\
\text { de idosos de um } \\
\text { centro de } \\
\text { convivência. }\end{array}$ & $\begin{array}{l}\text { Relato de } \\
\text { experiência. }\end{array}$ & Conexão UEPG \\
\hline 2018 & $\begin{array}{l}\text { Metodologias } \\
\text { ativas na } \\
\text { graduação em } \\
\text { enfermagem: um } \\
\text { enfoque na } \\
\text { atenção ao idoso }\end{array}$ & $\begin{array}{l}\text { SOUZA, E. F. } \\
\text { D.; } \\
\text { SILVA, A. G.; } \\
\text { SILVA, A. I. L. } \\
\text { F. }\end{array}$ & $\begin{array}{c}\text { Descrever a } \\
\text { experiência do uso } \\
\text { da simulação como } \\
\text { metodologia ativa } \\
\text { de ensino na } \\
\text { disciplina Psicologia } \\
\text { do Desenvolvimento } \\
\text { e compartilhar } \\
\text { repercussões no } \\
\text { processo de } \\
\text { aprendizagem dos } \\
\text { estudantes. }\end{array}$ & $\begin{array}{l}\text { Relato de } \\
\text { experiência. }\end{array}$ & $\begin{array}{c}\text { Revista } \\
\text { Brasileira de } \\
\text { Enfermagem }\end{array}$ \\
\hline 2019 & $\begin{array}{l}\text { Competências e } \\
\text { habilidades } \\
\text { desenvolvidas no } \\
\text { ensino clínico } \\
\text { prático em saúde } \\
\text { do adulto e } \\
\text { idoso: relato de } \\
\text { experiência } \\
\text { docente }\end{array}$ & $\begin{array}{l}\text { LEITE, C. N., } \\
\quad \text { et al. }\end{array}$ & $\begin{array}{c}\text { Refletir sobre a } \\
\text { experiência dos } \\
\text { docentes de } \\
\text { enfermagem ao } \\
\text { ministrarem a } \\
\text { disciplina de ensino } \\
\text { clínico prático em } \\
\text { saúde do adulto e } \\
\text { idoso na graduação. }\end{array}$ & $\begin{array}{l}\text { Relato de } \\
\text { experiência. }\end{array}$ & $\begin{array}{c}\text { Revista } \\
\text { Eletrônica } \\
\text { Acervo Saúde }\end{array}$ \\
\hline 2019 & $\begin{array}{l}\text { Contribuições da } \\
\text { metodologia da } \\
\text { problematização } \\
\text { na formação de }\end{array}$ & $\begin{array}{l}\text { PISSAIA,L. F., } \\
\text { et al. }\end{array}$ & $\begin{array}{l}\text { Compartilhar uma } \\
\text { experiência de } \\
\text { contribuições da } \\
\text { metodologia da }\end{array}$ & $\begin{array}{c}\text { Estudo } \\
\text { observacional, } \\
\text { descritivo e } \\
\text { reflexivo com }\end{array}$ & $\begin{array}{l}\text { Ensino, Saúde } \\
\text { e Ambiente }\end{array}$ \\
\hline
\end{tabular}




\begin{tabular}{|c|c|c|c|c|c|}
\hline & $\begin{array}{l}\text { cuidadores de } \\
\text { idosos }\end{array}$ & & $\begin{array}{l}\text { problematização que } \\
\text { foi desenvolvida na } \\
\text { formação de cinco } \\
\text { cuidadores de } \\
\text { idosos em uma } \\
\text { escola } \\
\text { profissionalizante do } \\
\text { interior do Rio } \\
\text { Grande do Sul, } \\
\text { Brasil. }\end{array}$ & $\begin{array}{l}\text { abordagem } \\
\text { qualitativa. }\end{array}$ & \\
\hline 2019 & $\begin{array}{l}\text { Projetos políticos } \\
\text { e pedagógicos de } \\
\text { residência de } \\
\text { enfermagem ao } \\
\text { idoso na } \\
\text { pesquisa freiriana }\end{array}$ & $\begin{array}{c}\text { RODRIGUES, } \\
\text { J. M. et al. }\end{array}$ & $\begin{array}{l}\text { Analisar os projetos } \\
\text { políticos e } \\
\text { pedagógicos de } \\
\text { residência de } \\
\text { enfermagem ao } \\
\text { idoso, na perspectiva } \\
\text { Freiriana. }\end{array}$ & $\begin{array}{c}\text { Estudo } \\
\text { descritivo, } \\
\text { exploratório, } \\
\text { abordagem } \\
\text { qualitativa e } \\
\text { análise } \\
\text { documental. }\end{array}$ & $\begin{array}{c}\text { Revista } \\
\text { Brasileira de } \\
\text { Enfermagem }\end{array}$ \\
\hline 2020 & $\begin{array}{c}\text { Avaliação do } \\
\text { conhecimento e } \\
\text { capacitação dos } \\
\text { ACS's acerca do } \\
\text { uso da escala de } \\
\text { depressão } \\
\text { geriátrica como } \\
\text { forma de triagem } \\
\text { de depressão em } \\
\text { idosos } \\
\text { cadastrados na } \\
\text { ESF do Parque } \\
\text { Verde em Belém- } \\
\text { PA }\end{array}$ & $\begin{array}{l}\text { FREITAS, C. } \\
\text { B., et al. }\end{array}$ & $\begin{array}{c}\text { Analisar o } \\
\text { conhecimento dos } \\
\text { Agentes } \\
\text { Comunitários de } \\
\text { Saúde sobre a } \\
\text { importância da sua } \\
\text { inserção e a sua } \\
\text { função em } \\
\text { reconhecer idosos } \\
\text { com risco de } \\
\text { depressão no } \\
\text { território da } \\
\text { Estratégia Saúde da } \\
\text { Família Parque } \\
\text { Verde, tendo como } \\
\text { instrumento a escala } \\
\text { de depressão } \\
\text { geriátrica. }\end{array}$ & $\begin{array}{c}\text { Estudo } \\
\text { quantitativo, } \\
\text { descritivo e } \\
\text { transversal. }\end{array}$ & $\begin{array}{c}\text { Brazilian } \\
\text { Journal of } \\
\text { Health Review }\end{array}$ \\
\hline
\end{tabular}

Fonte: autores, 2020.

No quadro 1 estão descritos os dados relativos aos artigos publicados nas bases de dados LILACS, Periódicos CAPES, Scielo e o buscador Google Acadêmico, no período de 2010 a junho de 2020. No que diz respeito à frequência de publicação, o ano com maior índice foi 2019, com 42,9\% (n=3) dos artigos. O restante dos trabalhos ocorreu em 2013, 2017, 2018 e 2020, todos com 14,3\% (n=1).

Ao analisar o periódico de publicação, 2 (28,6\%) foram publicados na Revista Brasileira de Enfermagem, 1 (14,3\%) Ensino Saúde e Ambiente, 1 (14,3\%) Brazilian Journal of Health Review, 1 (14,3\%) Cadernos de Graduação-Ciências Biológicas e da Saúde, 1 (14,3\%) Conexão UEPG e 1 (14,3\%) Revista Eletrônica Acervo Saúde. 
Em relação às palavras-chave que mais se repetiram estão: "Educação em enfermagem" (7,7\%); "Enfermagem" (7,7\%); "Idoso" (7,7\%); "Metodologias ativas" 7,7\%).

Quanto a metodologia empregada nestes estudos, 3 (42,9\%) caracterizaram-se como relato de experiência, 2 (28,6\%) dispuseram de abordagem qualitativa, 1 (14,3\%) de abordagem quantitativa e 1 (14,3\%) de abordagem mista.

\section{O uso de metodologias ativas para o ensino em saúde ao idoso}

Dentre as mudanças sociais que vêm sendo observadas em razão da crescente busca e inserção dos idosos, nos contextos onde antes não eram vistos, está a educação (OMS, 2015). Sabe-se que a educação tem grande potencial para promover melhorias à vida das pessoas e da sociedade como um todo, uma vez que reduz as iniquidades sociais, proporciona benefícios à saúde, trazendo mais anos de vida, além de possibilitar maior consciência política (PIERI, 2018).

"Se a educação sozinha não transforma a sociedade, sem ela tampouco a sociedade muda". Este excerto da Terceira Carta Pedagógica de Paulo Freire (2000) orienta para uma compreensão expandida da educação, que supere os limites da sala de aula, e se articule na multiplicidade política, ética, social e individual, de modo a contribuir para a construção de conhecimento que seja significativo e atue como fator de mudança (ANDREOLA, 2011).

Freire, em suas contribuições pedagógicas, suscitou a discussão sobre a educação bancária e a educação libertadora. A primeira caracteriza-se como um ato de depositar, onde se estabelece uma relação antidialógica entre educador-educando. Já a segunda se constitui por meio da ação-reflexão, do diálogo e na busca do homem por se reconhecer no mundo, com o mundo e com os outros (FREIRE, 1987). A ideia é que a prática educacional alcance um horizonte além de uma abordagem estritamente vertical, sem espaço para valorização dos saberes dos aprendentes, prejudicando o potencial que a educação tem para libertar.

Nesse sentido, levando em consideração o público idoso e sua necessidade de inserção nos cenários de educação a Política Nacional do Idoso, no terceiro inciso do artigo dez, descreve ações governamentais na área da educação, nas quais prevê: (a) adequação de currículos, metodologias e material didático aos programas educacionais destinados ao idoso; (b) inserção de conteúdos voltados ao envelhecimento nos diversos níveis de ensino formal; (c) inclusão da Gerontologia e da Geriatria como disciplinas curriculares nos cursos superiores; (d) desenvolvimento de programas educacionais que informem a população sobre o processo de envelhecimento; (e) desenvolvimento de programas que adotem modalidades de ensino à distância adequado aos idosos; ( $f$ ) 
incentivo à criação de universidades abertas para a terceira idade como forma de universalizar o acesso às diferentes formas do saber (BRASIL, 1994).

De forma semelhante à Política Nacional do Idoso, o Estatuto do Idoso prevê o direito à "educação, cultura, esporte, lazer, diversões, espetáculos, produtos e serviços que respeitem sua peculiar condição de idade" (BRASIL, 2003, art. 20). Além de reforçar alguns direitos já descritos na Política Nacional do Idoso, inclui também a inserção de conteúdos relativos aos avanços tecnológicos voltados à integração à sociedade moderna.

Devido a esse contexto a educação utiliza de estratégias pedagógicas, com o objetivo de socializar conhecimentos e contribuir para a formação de sujeitos, considerando as diversas relações humanas. A forma como se estabelecem essas relações, na articulação cotidiana do ensino-aprendizagem é ponto de discussão tendo em vista as manifestações que podem assumir (SOUZA, 2017).

Dentre as estratégias utilizadas destacam-se as metodologias ativas, que puderam ter seu uso constatado em dois dos sete artigos selecionados para essa revisão. No estudo de Alves, Rios e Rios (2013), destacou-se o uso de metodologias ativas baseadas em problemas, por acadêmicos do curso de Farmácia, para a educação de idosos acerca do uso correto de medicações, plantas medicinais, efeitos nocivos da automedicação e ações educativas voltadas para os benefícios da alimentação correta. Para a efetivação da metodologia foi utilizada uma atividade lúdica baseada em jogos, de modo a contribuir para o desenvolvimento do aprendizado.

Verifica-se aqui o emprego das metodologias ativas alinhadas com a prática de ações educativas, desse modo, a educação em saúde funciona como aporte para prevenir agravos, promover e recuperar a saúde em busca da qualidade de vida dos indivíduos e da comunidade, por intermédio dos saberes técnicos e populares. A compreensão acerca do público ao qual se destinam os esforços para promover educação em saúde constitui um desafio para aqueles que estão em processo de formação e para os profissionais de saúde, gestores e comunidade. Entende-se que existe uma tendência biomédica prevalente nas práticas assistenciais, assim como na visão popular, o que pode comprometer a abertura e adesão para práticas que busquem promover saúde por via da educação (SOUSA et al, 2010).

De forma semelhante o estudo de Oliveira et al (2017) propõe estratégias educativas por acadêmicos de Enfermagem com uma perspectiva metodológica baseada nas práticas de educação dialógicas propostas por Paulo Freire. A pesquisa em questão também utiliza a metodologia da problematização, propondo uma tecnologia de cuidado baseada em atividades lúdicas e técnicas grupais. 
Nesse sentido, percebe-se que ações educativas voltadas às práticas de atividades lúdicas com a população idosa trazem diversos benefícios e estimulam a independência e autonomia. Tais práticas influenciam nos aspectos psicológicos, biológicos e sociais (FLEURÍ et al., 2013). Cyrino et al. (2016) afirmam ainda que tais atividades proporcionam aos idosos o sentimento de pertencimento ao processo saúde-doença, assim como a contribuição para o desempenho cognitivo e funcional. Por fim, concluem que as práticas lúdicas atribuem significado no processo de construção do aprendizado e na promoção da saúde.

Silva, e colaboradores (2017), em seu estudo sobre ações educativas com idosos corroboram com os estudos de OLIVEIRA, et al. (2017) e ALVES, RIOS e RIOS (2013), reafirmando a importância do uso de metodologias ativas por meio do uso de jogos, teatros, passeios, entre outros. Essas práticas de ensino contribuem para o processo de aprendizagem, agregando benefícios para a formação do indivíduo em seus múltiplos aspectos. Desse modo a educação traz a valorização do ser humano, exercendo papel de influência nas necessidades individuais e coletivas além de atuar na promoção da saúde e prevenção de patologias. Assim, atividades como essas geram efeitos positivos na saúde do idoso contribuindo para o seu envelhecimento saudável e sua inserção na sociedade.

\section{O uso das principais metodologias ativas na formação de acadêmicos, profissionais e cuidadores}

As práticas educativas se modificam no decorrer do tempo. A educação, no século $X X$, sofreu forte influência de pensadores como Frenet, Monterrosi, Piaget, Vygotsky e Paulo Freire que deram início as discussões voltadas para práticas de ensino que proporcionassem a autonomia dos alunos (FARIAS; MARTINS; CRISTO, 2015).

Para Freire, a educação é a base transformadora da sociedade, pois, em seu livro Pedagogia do Oprimido (1987) cita "não é no silêncio que os homens se fazem, mas na palavra, no trabalho, na ação-reflexão. A educação sozinha não transforma a sociedade, sem ela tampouco a sociedade muda". Nesse sentido, pode-se entender que a educação deve estar aliada ao diálogo para a construção de um ser crítico, reflexivo e questionador. Para o autor, o saber se faz "na invenção, na reinvenção, na busca inquieta, impaciente, permanente, que os homens fazem no mundo, com o mundo e com os outros" (FREIRE, 1987).

Diante dessa ideia, o emprego das metodologias ativas é basilar para a construção de novas perspectivas pedagógicas. Elas proporcionam aos estudantes novas percepções que os possibilitam assumir uma postura ativa de modo a construir um 
aprendizado de forma autônoma, engajada, estimulando a busca pelo conhecimento significativo, reflexivo e que seja útil para a transformação do seu contexto social (COLARES; OLIVEIRA, 2018; DIESEL; BALDEZ; MARTINS, 2017).

Através das metodologias ativas, Souza, Silva e Silva (2018), relatam os benefícios que tais práticas oportunizam aos estudantes, proporcionando a inserção em ambientes simulados que os estimulam a atuarem frente a problemas, desenvolvendo assim segurança e autoconfiança para a futura prática profissional. Os autores concluem que essas práticas enriquecem o processo de ensino-aprendizado dos acadêmicos, oportunizando a formação de uma perspectiva que permita atender as necessidades dos sujeitos de forma holística. A formação acadêmica, mesmo tendo em sua essência a apreensão cognitiva de conceitos e procedimentos, se desenvolve em um contexto de interação em que se aprende com o outro, em processos de trocas que envolvem o corpo, a linguagem e, especialmente, os princípios em que se embasam tais manifestações.

Nesse sentido, o estudo de Leite e colaboradores (2019) aborda sobre as experiências dos docentes do curso de enfermagem, em uma disciplina destinada ao público adulto e idoso. Evidenciaram neste estudo a possibilidade de desenvolver competências e habilidades no ensino prático da graduação a partir de atividades propostas pela disciplina, oportunizando a abordagem de diversas temáticas que viabilizam a relação da prática orientada pela teoria.

Já no estudo de Rodrigues et al. (2017), os resultados evidenciados apontam para a reelaboração dos Projetos Políticos Pedagógicos (PPPs) para as residências de enfermagem. Foram analisados doze PPPs, nos quais os aspectos relacionados as dimensões problematizadora, humanística e dialógica, propostas pelo estudo, por vezes não estavam contempladas em todos os PPPs. Apenas um dos PPPs englobou todas as três dimensões, por oportunizar aos residentes cenários que possibilitam o desenvolvimento de uma postura reflexiva e ativa mediante situações reais, permeadas por atitudes humanizadas, éticas e baseadas no diálogo.

Dessa forma, as experiências de Souza, Silva e Silva (2018) e Leite et al (2019) corroboram com o estudo de Rodrigues et al. (2017), no sentido de consolidarem práticas acadêmicas com respaldo teórico político que garanta a execução prática dessas metodologias. Levando em consideração que o Projeto Político Pedagógico é o documento que norteia as ações de ensino dos cursos de graduação, entende-se que tanto a prática discente quanto a docente devem constar e ser embasadas mediante aos PPPs dos cursos. 
Entretanto, eventualmente, os Projetos não contemplam todas as demandas de práticas pedagógicas percebidas no cotidiano acadêmico ou de exercício profissional. É importante ressaltar que o emprego das metodologias ativas não depende somente da reestruturação dos currículos dos cursos, que por vezes tem delineamentos superficiais e fragmentados. Logo, a postura docente é ponto crucial para o desenvolvimento dos objetivos metodológicos que devem estar alinhados com seus princípios pedagógicos originários, pois esse comprometimento em promover o ensino de forma alinhada garante a eficácia da utilização de diversas metodologias ativas (SIMON et al, 2015).

Levando em consideração ainda os resultados encontrados neste estudo, Pissaia et al (2019) afirmam o uso da metodologia da problematização para a formação de cuidadores de idosos de uma escola profissionalizante. Através da problematização os cuidadores puderam visualizar o percurso formativo e as características necessárias ao cuidador, refletindo acerca das práticas do processo de cuidado de forma crítica, visualizando assim, os principais erros e acertos que ocorrem diante dessa profissão.

Observou-se que em grande parte dos artigos da amostra as principais tendências pedagógicas abordadas voltaram-se para o uso da metodologia da problematização. As ideias presentes nos artigos encontrados tinham princípios problematizadores ligados a atividades lúdicas como jogos, teatro e simulações, despertando os estudantes e profissionais da área da saúde para assumirem o papel principal na construção do seu ensino-aprendizado de forma ativa e autônoma, ressaltando assim a principal essência do emprego dessas metodologias. Verifica-se ainda no estudo de Paiva et al (2016), que a problematização atua na transformação do conhecimento, uma vez que sua proposta se pauta nas resoluções de problemas que levam o indivíduo a pensar e inserir-se no contexto problematizador de forma a construir um saber significativo.

Para Freitas et al (2020) o uso da metodologia ativa foi aplicado com objetivo de identificar o conhecimento dos ACS de uma equipe da Estratégia de Saúde da Família (ESF) acerca do uso da escala de depressão em idosos. O estudo foi realizado por fases, permitindo o monitoramento sobre a relação de conhecimento dos ACS antes e após o uso da metodologia. Na primeira fase, foi aplicado um questionário de conhecimento acerca do assunto, na segunda fase, os participantes responderam três perguntas, seguida de uma palestra. Na terceira fase, foi aplicado outro questionário para reavaliar o conhecimento adquirido após a explanação. Evidenciou-se que houve uma melhora significativa de conhecimento dos participantes, ressaltando que o uso dessa ferramenta torna-se cada vez mais efetiva para a educação em saúde.

É importante evidenciar que o estudo acima citado não traz o nome da metodologia aplicada, usando técnicas tradicionais como palestra expositiva e aplicação 
de questionários para o desenvolvimento da metodologia. Devido a esse tipo de experiência, Sobral e Campos (2012) citam em seu estudo, que algumas práticas evidenciadas nos artigos também estavam ligadas a metodologias tradicionais atreladas a educação conservadora, porém, devido ao uso de uma dinamicidade para o ensino, foram caracterizadas como metodologias ativas. Assim, entende-se a necessidade de unir e fundamentar as metodologias ativas as teorias do conhecimento, uma vez que, algumas técnicas que são colocadas como inovadoras são apenas metodologias antigas aprimoradas.

\section{Considerações Finais}

Esta revisão sistemática analisou as práticas em metodologias ativas utilizadas no ensino de saúde de idosos. Entre os resultados encontrados pode-se verificar em alguns dos estudos, que as práticas metodológicas ativas não foram de fato contempladas. A apropriação do uso destas, por vezes, foram percebidas como uma disseminação equivocada das metodologias ativas, através do ensino tradicional.

Notou-se que com o aumento do envelhecimento populacional, faz-se necessário que as formações em saúde agreguem práticas voltadas aos novos contextos, contemplando as novas demandas sociais. No ambiente acadêmico as abordagens feitas através das metodologias ativas favorecem para a inserção profissional, possibilitando ao discente o desenvolvimento do pensamento crítico, da autonomia e do engajamento, que irão contemplar essa prática.

Tendo em vista os trabalhos apresentados, sugere-se a necessidade de mais pesquisas referentes ao uso de metodologias ativas voltadas ao ensino de saúde do idoso, tanto no âmbito acadêmico, quanto em outros contextos de ensino, como a educação em saúde e permanente.

\section{Referências}

ALVES, M. I. G.; RIOS, P. S. S.; RIOS, M. C. (2013). O impacto do estágio na formação do farmacêutico no cuidado ao paciente idoso. Cadernos de Graduação - Ciências Biológicas e da Saúde. v. 1, n. 2.

ANDREOLA, B. A. (2011). Por uma pedagogia das grandes urgências planetárias. Educação. Santa Maria, v. 36, n. 2, p. 313-30.

BARDIN, L. Análise de Conteúdo. (2011). NETO, L. A.; PINHEIRO, A. (trad.). Ed. 70. BERBEL, N. A. N. (2011). As metodologias ativas e a promoção da autonomia de estudantes. Semina: Ciênc. Sociais e Humanas. v. 32, n. 1, p. 25-40.

BRASIL. (2017, dez 08). Ministério da Saúde. Conselho Nacional de Saúde. Resolução nº 569.

BRASIL. Lei no 8.842, Política Nacional do Idoso. (1994). DF, v. 132, n. 3, p. 1-3.

BRASIL. Lei no 1.074, Estatuto do Idoso. (2003). DF. 
CAMARANO, A. A. A. (2008). demografia e o envelhecimento populacional. In: FUNDAÇÃO OSWALDO CRUZ. Escola Nacional de Saúde Pública Sergio Arouca. Educação a Distância. Envelhecimento e saúde da pessoa idosa. Borges, A. P. A. Coimbra, A. M. C. (org.). Rio de Janeiro: EAD/ENSP, 340 p.

CARVALHO, C. R. A. (2015). A Saúde do Idoso no ensino superior de universidades públicas do Rio de Janeiro: o caso dos cursos de Educação Física, Enfermagem e Nutrição. Tese (doutorado). $85 \mathrm{f}$.

CACHIONI, M.; TODARO, M. A. (2016). Política nacional do idoso: reflexão acerca das intenções direcionadas à educação formal. In: ALCÂNTARA, A. O.; CAMARANO, A. A.; GIACOMIN, K. C (eds.). Política Nacional do Idoso: velhas e novas questões. Rio de Janeiro: IPEA. p.457-78.

COLARES, K. T. P.; OLIVEIRA, W. (2018). Metodologias ativas na formação profissional em saúde: uma revisão. Revista Sustinere. RJ, v. 6, n. 2, p. 300-20.

CYRINO, R. S. et al. (2016). Atividades lúdicas como estratégia de educação em saúde com idosos. Rev. Ciênc. Ext. v. 12, n. 3, p. 154-63.

DIESEL, A.; BALDEZ, A. L. S.; MARTINS, S. N. (2017). Os princípios das metodologias ativas de ensino: uma abordagem teórica. Revista Thema. v. 14, n. 1.

DUARTE, S. M. Os impactos do modelo tradicional de ensino na transposição didática e no fracasso escolar. Dissertação (mestrado). 2018. $121 \mathrm{f}$.

FARIAS, P. A. M.; MARTIN, A. L. A. R.; CRISTO, C. S (2015). Aprendizagem Ativa na Educação em Saúde: Percurso Histórico e Aplicações. Rev. bras. educ. med. [online]. vol.39, n.1, pp.143-150.

FELIPE, T. W. S. S.; SOUSA, S. M. N (2018). Gênero e geração: os significados atribuídos à velhice e o que torna possível a distinção entre os sujeitos definidos como idosos. Cad. Eletrônico de Ciências Sociais: Cadecs, v. 6, n. 2, p. 32-53.

FLEURÍ, A. C. P. et al. (2013). Atividades lúdicas com idosos institucionalizados. Rev. Enfermagem Revista. v. 16. n. 01. jan-abr.

FREIRE, P. Pedagogia do oprimido (1987). Paz e Terra. RJ, $17^{a}$ ed. 107 p.

FREITAS, C. B. et al. (2020). Avaliação do conhecimento e capacitação dos agentes comunitários de saúde acerca do uso da escala de depressão geriátrica como forma de triagem de depressão em idosos cadastrados na ESF do Parque Verde em Belém do Pará. Braz. J. Hea. Rev. Curitiba, v. 3, n. 2, p. 2342-2354.

LEITE, C. N. et al. (2019). Competências e habilidades desenvolvidas no ensino clínico prático em saúde do adulto e idoso: relato de experiência docente. REAS/EJCH v. sup. 29, e1341.

MINAYO, M.C.S (1992). O desafio do conhecimento: pesquisa qualitativa em saúde. $5^{a}$ ed. São Paulo: Hucitec.

MELO, F (2017). Envelhecer não é um fardo. Rio de Janeiro: Radis, v. 173, p. 22.

MENEZES, M. G.; SANTIAGO, M. E (2014). Contribuição do pensamento de Paulo Freire para o paradigma curricular crítico-emancipatório. Pro-Posições, v. 25, n. 3, p. 4562.

NETO, J. M. R. et al. (2016). Análise de teorias de enfermagem de Meleis: revisão integrativa. Rev Bras Enferm [Internet]. v. 69, n. 1, p. 174-81, jan-fev.

OLIVEIRA, F. A. et al. (2017). Estratégias educativas para promoção da saúde de idosos de um centro de convivência. Revista Conexão UEPG. v. 13 n. 3, set-dez.

ORGANIZAÇÃO MUNDIAL DE SAÚDE. (2015). Relatório mundial de envelhecimento e saúde. $28 \mathrm{p}$.

PAIVA, M. R. F. et al. (2016). Metodologias ativas de ensino-aprendizagem: revisão integrativa. Sanare. Sobral, v. 15, n. 02, p. 145-153, jun-dez.

PIERI, R. (2018). Retratos da educação no Brasil. Instituto de Ensino e Pesquisa.

PISSAIA, L. F. et al. (2019, abril). Contribuições da metodologia da problematização na formação de cuidadores de idosos. Ensino, Saúde e Ambiente. v. 12, n. 1, p. 143159. 
RODRIGUES, J. M. et al. (2019). Projetos políticos e pedagógicos de residência de enfermagem ao idoso na perspectiva freiriana. Rev Bras Enferm. v. 72, Suppl 2, p. 41-7.

SILVA, W. et al. (2017). Ações educativas vivenciadas com idosos: Um relato de experiência. Rev. Ciênc. da Saúd Nova Esperança, v. 15, n. 3, p. 31-36.

SIMON, E. et al. (2015). Metodologias ativas de ensino-aprendizagem e educação popular: encontros e desencontros no contexto da formação dos profissionais de saúde. Interface-Comunic., Saúde, Educação, v. 18, p. 1355-1364.

SOBRAL, F. R.; CAMPOS, C. J. G. (2012). Utilização de metodologia ativa no ensino e assistência de enfermagem na produção nacional: revisão integrativa. Rev Esc Enferm USP. v. 46, n. 1, p. 208-18.

SOUZA, E. F. D.; SILVA, A. G.; SILVA, A. I. L. F. (2018). Metodologias ativas na graduação em enfermagem: um enfoque na atenção ao idoso. Rev. Bras. Enferm. Brasília, v. 71, supl. 2, p. 920-924.

VERAS, R. P.; OLIVEIRA, M. (2018). Envelhecer no Brasil: a construção de um modelo de cuidado. Ciênc. \& Saúd. Colet. RJ, v. 23, n. 6, p. 1929-1936.

VIANA, C. et al. (2013). Capacidade funcional de idosos do concelho de Baião. In: SOUZA, D. N.; RUA, M. S. (coord.). Cuidadores informais de Pessoas idosas: caminhos de mudança. Aveiro: UA Editora. p. 320-25.WODAK, R., \& MEYER, M. (2001). Methods of Critical Discourse Analysis. Londres: Sage Publications.

\begin{abstract}
:
This research aimed to analyze the practices in active methodologies used in health education for the elderly. The sample search was carried out in the LILACS, SciELO, CAPES journals and Google Scholar search databases. Seven articles were selected and their analysis resulted in the categories "the use of active methodologies for teaching health to the elderly" and "the use of the main active methodologies in the training of academics, professionals and caregivers". Current social demands require teaching methodologies that enable critical, reflective and problematizing training. The need for more research on this topic is suggested, both in the academic sphere and in other teaching contexts, such as health and permanent education.
\end{abstract}

KEYWORDS: Active methodologies; Health; Aged.

\begin{abstract}
RESUMEN:
Esta investigación tuvo como objetivo analizar las prácticas en metodologías activas utilizadas en la educación sanitaria para los ancianos. La muestra se buscó utilizando las revistas LILACS, SciELO, CAPES y Google Scholar. Se seleccionaron siete artículos y su análisis dio como resultado las categorías "el uso de metodologías activas para enseñar la salud a los ancianos" y "el uso de las principales metodologías activas en la formación de académicos, profesionales y cuidadores". Las demandas sociales actuales requieren metodologías de enseñanza que permitan una capacitación crítica, reflexiva y problemática. Sugerimos la necesidad de más investigación sobre este tema, tanto en el ámbito académico como en otros contextos de enseñanza, como la salud y la educación permanente.
\end{abstract}

PALABRAS-CLAVES: Metodologías activas; Salud; Anciano. 